\title{
Examining students' use of online annotation tools in support of argumentative reading
}

Jingyan Lu

The University of Hong Kong, Hong Kong, China

\author{
Liping Deng \\ Hong Kong Baptist University, Hong Kong, China
}

\begin{abstract}
This study examined how students in a Hong Kong high school used Diigo, an online annotation tool, to support their argumentative reading activities. Two year 10 classes, a high-performance class (HPC) and an ordinary-performance class (OPC), highlighted passages of text and wrote and attached sticky notes to them to clarify argumentation structures and to represent and share argumentation processes. Analysis of annotations revealed that highlighting was the most frequently used online annotation feature. The HPC made significantly more sticky notes and used them more to annotate terms, claims and judgments than the OPC. The study suggests that Diigo is a promising tool for supporting reading-to-argue. The findings may be of value to teachers and researchers in designing online annotation tools that more effectively foster the process of reading-to-argue.
\end{abstract}

\section{Introduction}

Argumentation refers to a way of thinking and interacting in everyday life (Kuhn, 1991). In school, argumentation skills are critical to such basic learning activities as reading and writing. However, students often have difficulty when it comes to writing arguments because it requires them to "transform source texts into well-reasoned claims that address a specific issue" (Higgins, 1993, p. 73). During the period of active reading that precedes the writing of arguments, students interpret texts and extract and organise relevant ideas, concepts and expressions. Unfortunately, instruction typically focuses on the writing process or the written product, not on reading-to-argue (Higgins, 1993). Although, written arguments are often used to differentiate student performance, annotations or the products of the process of reading-toargue have seldom been examined for this purpose.

The Internet is a large and rich source of information and teachers need to help students read online texts. Specifically, students need tools that allow them to annotate passages of text in order to identify positions, claims, and opinions. This study explores how Diigo (http://www.diigo.com) was adopted in supporting the process of reading-to-argue in Liberal Studies (LS), a new core subject in Hong Kong high schools. Hong Kong's LS program seeks to provide students with "opportunities to explore issues relevant to the human condition in a wide range of contexts and enable them to understand the contemporary world and its pluralistic nature" (Education and Manpower Bureau, 2007, p. 2). It is intended to help students develop the ability to read critically and to write well-reasoned arguments. Diigo (Digest of Internet Information, Groups and Other stuff) was selected because it allows students to highlight web pages and attach comments as sticky notes, and to browse the online annotations of others (Greenhow, 2009). It also allows students to collaborate by interacting with and commenting on the annotations of peers. This study seeks to determine whether students who perform at different academic levels differ in their use of the read-to-argue behaviours supported by Diigo.

\section{Literature review}

\section{Argumentation skills}

Students need content knowledge and argumentation skills to produce well-written arguments. Although teachers have long recognised the importance of argumentation skills, they rarely teach them explicitly. Educational researchers also have noted that students have weak argumentation skills. For example, many students cannot understand argumentative discourse (Reznitskaya, Anderson, McNurlen, Nguyen-Jahiel, Archodidou, \& Kim, 2001), they cannot generate counter-arguments (Stein \& Bernas, 1999) and they frequently rely on personal beliefs in place of evidence (Brem \& Rips, 2000; Glassner, Weinstoc, \& Neuman, 2005). Argumentation involves the exercise of reasoning skills to assert, defend, and refute 
claims in pursuit of goals. It has been argued that argumentation is a general socio-cognitive process that involves specific forms of reasoning (Oaksford, Chater, \& Hahn, 2008), decision-making, and problemsolving (Driver, Newton, \& Osborne, 2000; Nussbaum, 2002).

Well-reasoned arguments contain appropriate claims, sound explanations supported by evidence, alternative opinions and well-elaborated concepts (Kuhn, 1991; Toulmin, 1958). Claims express the conclusions of arguments (Toulmin, 1958) and making claims is a developmental skill (Knudson, 1992). The ability to express opinions on issues and to identify and evaluate the opinions of others is the basis to argumentation skills (Kuhn, 2001). The ability to provide adequate evidence to support claims (Felton \& Kuhn, 2001; Kuhn, 1991) is another skill that students have trouble developing. Students often support their arguments with insufficient or inconclusive evidence (Kuhn, 2001; Walton, 1996). Further, "formulating and weighting the arguments for and against a course of action, a point of view, or a solution to a problem" (Kuhn, 1991, p. 2) are essential for developing multiple perspectives and counterarguments, yet these are exactly what is missing in written arguments of most high-school students (Felton, 2004). Finally, students must be able to understand, elaborate, and discuss concepts that can lead to changes in their understanding and acquisition of new perspectives (Asterhan \& Schwarz, 2009).

Understanding how arguments work and developing effective argumentation skills go hand-in-hand. Students need to read-to-argue (Felton, 2004) to produce well-reasoned arguments. Reading-to-argue involves the ability to critically read and evaluate source texts. It involves comprehending, analysing and remembering text. To achieve this, students can use annotation, a reading strategy that can help them recognise different perspectives in source texts, think through issues, evaluate opinions, and reflect on their own ideas (Wolfe, 2008). Reading-to-argue can induce students to criticise what they read rather than simply summarise it. The following sections will focus on how annotation can support both paperbased and online reading.

\section{Paper-based annotation}

An annotation is characterised as "a datum created and added by a third party to the original document" (Ovsiannikov, Arbib, \& McNeill, 1999, p. 340). As a reading strategy, annotating involves creating place markers to signal important information. It may involve underlining or highlighting stretches of text, and appending notes to them (Marshall, 1997). Ovsiannikov et al. (1999) maintained that readers annotated in order to remember, reflect on, clarify, reorganise, rephrase, and share important information. Annotation can enhance comprehension and learning because it requires readers to pay more attention and to engage in higher-level cognitive processing (Anderson \& Armbruster, 1982). In an examination of the effectiveness of annotation among college freshmen, Simpson and Nist (1990) reported that the annotating group out-performed the non-annotating group on comprehension tests. Further, by annotating as they read, readers focused their attention on important points and constructed explicit relationships between them (O'Hara \& Sellen, 1997). Annotating is especially helpful in working with written arguments because it bridges the gap between reading-to-argue and writing arguments (Wolfe \& Neuwirth, 2001).

\section{Online annotation}

As students come to rely more on online texts, the need increases for online annotation tools to support their ability to access, manage, share and interact with digital texts (Wolfe, 2002) across time and space (Rau, Chen \& Chin, 2004). Early online annotation tools had a number of limitations. They were cumbersome and interfered with the reading process (O'Hara \& Sellen, 1997) by displaying annotations and annotated texts in separate windows (Nokelainen, Miettinen, Kurhila, Floréen \& Tirri, 2005). More recent online annotation tools such as Diigo have overcome these limitations and now support integrated and smooth online annotation.

Research on online annotation is in its infancy, and has thus far focused more on technical issues such as designing and developing tools (e.g., Glover, Xu, \& Hardaker, 2007; Rau, et al., 2004). Research on the pedagogical design, implementation and impact of online annotation tools is as yet limited. Nokelainen and colleagues (2005) have demonstrated the positive learning effects of EDUCOSM, a web-based document-annotation tool. They found that students' engagement with EDUCOSM to be related to their learning. Students recognised the positive effects of EDUCOSM on their learning habits as well. Johnson, 
Archibald and Tenenbaum (2010) reported studies on the effects of an online social annotation tool (HyLighter) on college students' reading comprehension, critical thinking and meta-cognitive skills. They found students who collaborated in small groups with Diigo were better at reading comprehension and meta-cognitive skills. Hwang, Shadiev, and Huang (2011) conducted an experimental study involving a multimedia web annotation tool (Vpen) among high-school students, finding that the use of Vpen was significantly correlated with their speaking and writing performance. On the whole, the implementation of online annotation tools in both tertiary and K-12 settings has shown some promising results. However, more research is certainly needed to elucidate how the tools can be pedagogically designed and how students actually use the tools to support their learning.

\section{Context}

The Hong Kong Liberal Study program consists of modules dealing with topics in six themes: Personal development and interpersonal relationships, Hong Kong today, Modern China, globalisation, public health and energy technology and the environment. Modules are composed of six 45-minute class sessions.

In this study, participating teachers used Diigo's educator account to create accounts for students and to organise them into groups of three to four students. Diigo was integrated into a module focusing on whether Hong Kong should construct a high-speed rail system. Six Liberal Studies teachers collaboratively designed this module, and the two classes used the same teaching materials and activities. Teachers selected news articles and editorial comments from online newspapers and assigned them to both a high-performance class (HPC) and an ordinary-performance class (OPC) as reading materials. Students were free to select any articles they wanted, and they often searched school-subscribed online news databases. Students first annotated teacher-assigned and self-selected online texts by themselves. Then they collaboratively reviewed and commented on the texts annotated by other members of their group.

\section{Research questions}

To write well-reasoned arguments, students must first carefully read and critically analyse the relevant source texts. Annotating is a useful reading strategy for highlighting, labelling, analysing and summarising the parts of arguments in preparation for writing well-reasoned composite arguments. In examining how students used Diigo to bridge the gap between reading-to-argue and writing-to-argue, we focused on the following research questions:

1. How do students make annotations? Do the annotations of the high-performance class (HPC) and the ordinary-performance class (OPC) differ, and if so, how?

2. How are sticky notes used in reading-to-argue? Do the HPC and OPC differ?

3. How do students interact through Diigo?

\section{Methods}

\section{Participants}

Two classes of year 10 students, a high-performance class (HPC) and an ordinary-performance class (OPC), in a public Hong Kong high-school were recruited for the study. Students were separated based on high school entrance exam scores. The top 44 students were put into the HPC; the rest were put into OPCs. One OPC was randomly selected to participate in the study together with the HPC. Participating teachers and students received training on Diigo and were allowed to practice with it before the study began. By excluding students who did not use Diigo due to their absence from the class, there were 43 participants in the HPC and 30 in the OPC. These classes were selected to determine whether their use of Diigo in annotating texts varied. The ultimate aim of the study was to determine ways help teachers and researchers design online annotation activities and address the needs of diverse learners. 


\section{Procedure}

The design of online annotation task was based on Kuhn's (1991) and Toulmin's (1958) model of argumentation. It involved identifying claims, alternative opinions, explanations and evidence. Diigo was used to support reading-to-argue in several ways. First, identifying and understanding key concepts and issues are prerequisites to constructing good arguments. Diigo supports these tasks with its highlighting and sticky-notes features. On the first teacher-assigned article, students were instructed to highlight key concepts and use sticky notes to define or explain them. Second, students used Diigo to identify the positions of different stakeholders and to differentiate evidence from opinion. On the second teacherassigned article, students highlighted the positions of different stakeholders in different colours and noted their positions on sticky notes. In Figure 1, one student marked key concepts in green, pro positions in pink and con positions in blue. Teachers gave students an analytical matrix containing argumentation tags, such as "Pro position (support)" and "Con position (against)", which they could add as sticky notes after highlighting relevant portions of texts. Figure 1 shows how a student attached a "pro" tag to a stretch of highlighted text. Students were also encouraged to use sticky notes to post and exchange opinions, comments and conclusions.

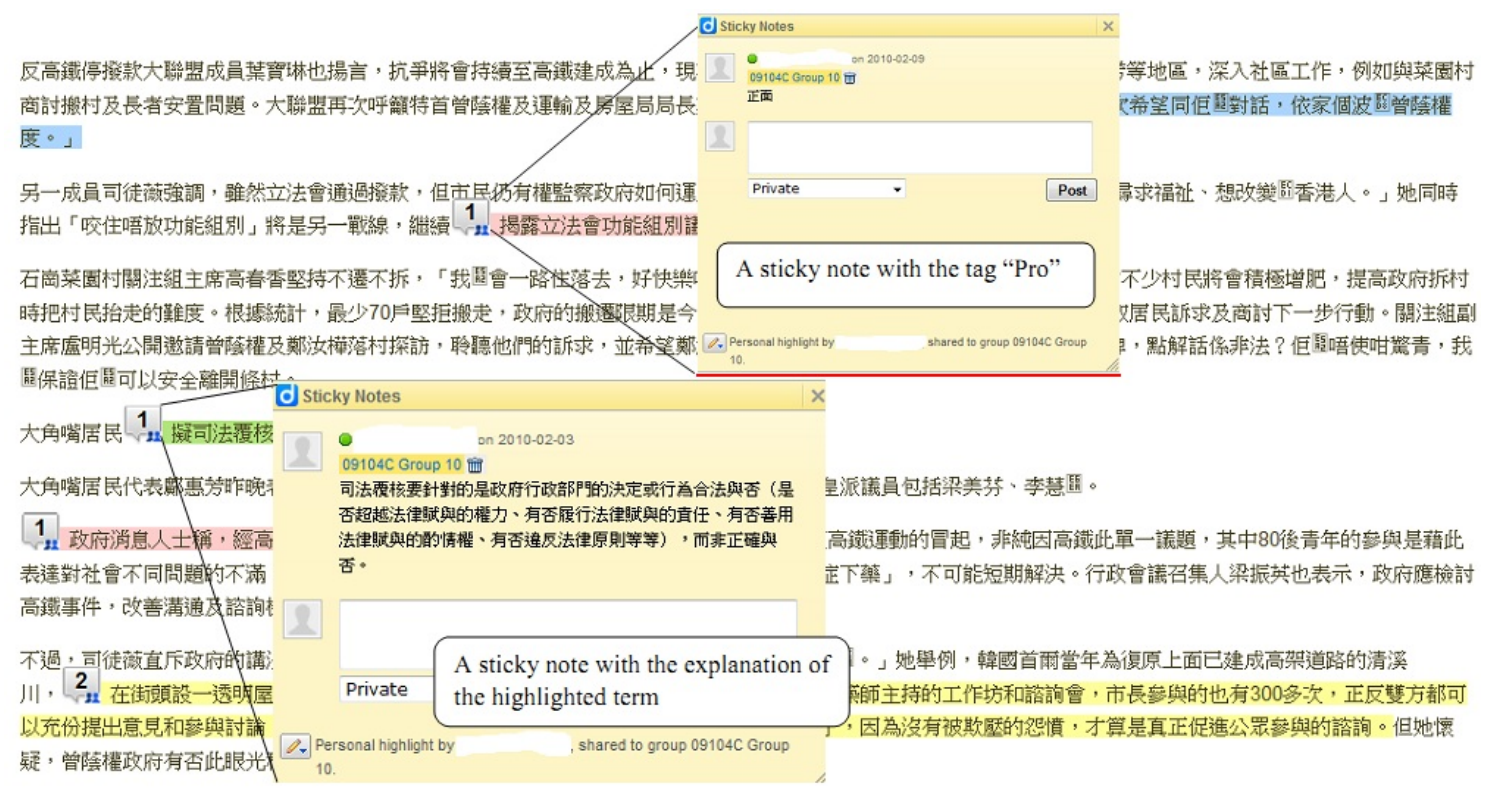

Figure 1. Screenshot of an annotated page.

The annotation tasks on teacher-selected articles were rather structured, while the annotation tasks for student-selected articles were more open-ended. Students could choose which feature to use and how to use it. After annotating teacher-selected and self-selected texts, students shared them in Diigo's group space, where group members were encouraged to use sticky notes to review and comment on each other's work. Finally, students could edit or revise their annotations based on the feedback.

\section{Data collection and analysis}

Computer annotations were manually extracted from the Diigo website and recorded in a database. Annotation data included the occurrences of highlights, sticky notes and comments exchanged among group members, and the contents of posted sticky notes. Descriptive data concerning annotation behaviour, such as the number of highlights and sticky notes, was calculated. We also used content analysis to investigate how students used the sticky-notes feature to support reading-to-argue.

Both the annotation tasks and the coding scheme for sticky notes were adapted from Toulmin's (1958) widely accepted analytical framework. In their review of various approaches to argumentation, Clark, Sampson, Weinberger, and Erkens (2007) observed that researchers typically adopted theoretical or analytical frameworks that drew on Toulmin's (1958) analysis of arguments as composed of six 
components: (1) claims or conclusions, (2) evidence supporting claims; (3) warrants relating claims to evidence; (4) qualifiers presenting arguers' degree of certainty about claims; (5) backings that provide justifications for warrants; and (6) rebuttals of statements acknowledging the limits of claims. Toulmin's model has been used in different subject domains (Chang \& Chiu, 2008; Erduran, Simon, \& Osborne, 2004; Osborne, Erduran, \& Simon, 2004). Some researchers have simplified the model by collapsing categories to improve the clarity and reliability of analysis (e.g., Erduran, et al., 2004). Based on Toulmin's theoretical frameworks and the task nature of this study, we identified four categories of sticky notes: (1) definition, (2) positions, (3) explanation or evidence and (4) claim or conclusion (Table 1 gives the coding scheme and examples).

Table 1

Coding scheme of reading-to-argue sticky notes

\begin{tabular}{|c|c|c|}
\hline Category & Definition & Examples \\
\hline Definition & Defining key terms or concepts. & $\begin{array}{l}\text { On a sticky note attached to the highlighted } \\
\text { term "the Greater Pearl River Delta" was } \\
\text { written "Comprising Hong Kong and nine } \\
\text { municipalities of the Guangdong Province in } \\
\text { the mainland of China and Macau". }\end{array}$ \\
\hline Positions & $\begin{array}{l}\text { Identifying and analysing } \\
\text { different positions. Notes } \\
\text { assigned to this category were } \\
\text { usually guided by teacher } \\
\text { suggested tags such as pro or for } \\
\text { and con or against. }\end{array}$ & $\begin{array}{l}\text { On a sticky note attached to the highlighted } \\
\text { paragraph "Minister of Transportation } \\
\text { Department emphasised that citizens could } \\
\text { oversee this procedure" was labelled as "pro". }\end{array}$ \\
\hline $\begin{array}{l}\text { Explanation } \\
\text { or evidence }\end{array}$ & $\begin{array}{l}\text { Giving explanations or evidence } \\
\text { to an issue or a claim. }\end{array}$ & $\begin{array}{l}\text { On a sticky note attached to the highlighted } \\
\text { paragraph "the conflict between government } \\
\text { and the citizens" was written "The reasons for } \\
\text { the conflict were due to the short consultation } \\
\text { period". }\end{array}$ \\
\hline $\begin{array}{l}\text { Claim or } \\
\text { conclusion }\end{array}$ & $\begin{array}{l}\text { Students state their opinions or } \\
\text { draw conclusions from the } \\
\text { claims. }\end{array}$ & $\begin{array}{l}\text { A sticky note written "the practical } \\
\text { implication is rather limited" was attached to } \\
\text { the highlighted sentence "the railway can } \\
\text { benefit at most } 400,000 \text { people in Hong } \\
\text { Kong". }\end{array}$ \\
\hline
\end{tabular}

Exchanged comments and sticky notes were examined separately, as they involved different types of activities: the sticky notes were used to aid individual students in reading-to-argue, while exchanged comments involved students in a group reviewing each other's work and exchanging ideas. To better understand the nature of students' online interactions, we first classified exchanged comments into two groups based on their overall purposes: (1) responses to highlighted text or sticky notes and (2) comments on annotation behaviours. The first type dealt with content-related discussions (e.g. "I think their (students') behaviours were too radical"), whereas the second type resulted from the peer review of annotation behaviours (e.g. "It would be better if more explanations could be provided in the sticky note"). We also examined the content of the comments following a data-driven process of identifying themes and categorisation, which resulted in four types of comments: (1) an opinion or claim (e.g. "I think the government made a hasty decision"); (2) additional evidence or information; (3) agreement (e.g. "Very detailed explanation"); and (4) questions or challenges (e.g. "But the high speed rail is too expensive. Will people choose the regular railway?"). The second author and a research assistant coded the notes separately; the inter-rater reliability was .82 on sticky notes and .86 on comments. 


\section{Results}

\section{Annotation behaviours of HPC and OPC}

We calculated the number of students who used the highlighting and sticky-notes features and the number of highlights and sticky notes they produced. The students in both classes used highlighting most $(100 \%$ of HPC students and 97\% OPC students), and sticky notes second-most often (100\% in the HPC and $77 \%$ in the OPC). Students' annotation behaviours on self-selected articles were singled out, as we believe their performance on these articles would better present their tendency and pattern of usage in a less controlled environment. Differences between the two classes were more dramatic with respect to self-selected articles. Whilst most students in both classes (93\% in the HPC and 73\% in the OPC) highlighted selfselected articles, the percentage of sticky-note use dropped sharply to $27 \%$ in the OPC while remaining quite high at $73 \%$ in the HPC (Table 2).

Table 2

Use of annotation features

\begin{tabular}{ccccc}
\hline & All articles & \multicolumn{2}{c}{ Self-selected articles } \\
\hline & Highlights & Sticky notes & Highlights & Sticky notes \\
HPC & $43(100 \%)$ & $43(100 \%)$ & $40(93 \%)$ & $34(79 \%)$ \\
OPC & $29(97 \%)$ & $23(77 \%)$ & $22(73 \%)$ & $8(27 \%)$ \\
\hline
\end{tabular}

With respect to annotations, the HPC produced 965 highlights $(\mathrm{M}=22)$ and 502 sticky notes $(\mathrm{M}=12)$, and the OPC produced 544 highlights $(\mathrm{M}=18)$ and 114 sticky notes $(\mathrm{M}=4)$ (Table 3$)$. The number of sticky notes created per OPC student was significantly less than the number created per HPC student $(t=$ 5.07, $p<.001)$. With respect to self-selected articles, students on average made fewer highlights $(8$ for HPC, 9 for OPC) and fewer sticky notes ( 5 for HPC, 2 for OPC). Still, the OPC produced significantly fewer sticky notes than the HPC $(t=3.33, p=.002)$.

Table 3

Descriptive data of students' annotation

\begin{tabular}{lcccccccc}
\hline & \multicolumn{9}{c}{ All articles } & \multicolumn{5}{c}{ Self-selected articles } \\
\cline { 2 - 8 } & Min & Max & M & Total & Min & Max & M & Total \\
HPC (n=43) & & & & & & & & \\
Highlights & 0 & 36 & 22 & 965 & 0 & 18 & 8 & 328 \\
Sticky notes & 0 & 23 & 12 & 502 & 0 & 13 & 5 & 235 \\
OPC (n=30) & & & & & & & & \\
Highlights & 0 & 74 & 18 & 544 & 0 & 47 & 9 & 282 \\
Sticky notes & 0 & 38 & 4 & 114 & 0 & 24 & 2 & 55 \\
\hline
\end{tabular}

\section{The use of the sticky-notes feature}

A content analysis of sticky notes revealed that about half the notes created by both classes $(52 \%$ for the HPC; $47 \%$ for the OPC) involved adding definitions or further information to highlighted text. The second-largest category of sticky notes for both classes involved giving explanations or evidence $(26 \%$ for the HPC; $38 \%$ for the OPC). The classes were similar in their use of teacher-suggested tags for identifying and analysing positions (16\% for the HPC, $12 \%$ for the OPC). The last category - making a claim or conclusion - was used much less frequently: in only $6 \%$ of HPC sticky notes and $3 \%$ of OPC sticky notes. Comparing the means of the four categories revealed that the HPC added significantly more explanations of terms $(t=5.36, p<.001)$ and made more claims or conclusions $(t=3.01, p=.004)$ than the OPC. No significant differences were detected for the other two categories (Table 4). 
Table 4

Comparison of HPC and OPC sticky note use

\begin{tabular}{|c|c|c|c|c|c|c|}
\hline & M & SD & $\%$ & $t$ & $D f$ & $p$ \\
\hline Defining terms & & & & 5.36 & 71 & .000 \\
\hline $\mathrm{HPC}$ & 5.26 & 2.51 & 52 & & & \\
\hline $\mathrm{OPC}$ & 1.77 & 3.04 & 47 & & & \\
\hline \multicolumn{4}{|c|}{ Identifying and analysing opinions } & 1.90 & 66.28 & .062 \\
\hline HPC & 1.65 & 3.58 & 16 & & & \\
\hline $\mathrm{OPC}$ & .43 & 1.85 & 12 & & & \\
\hline Giving explanations & & & & 1.46 & 71 & .149 \\
\hline $\mathrm{HPC}$ & 2.67 & 2.88 & 26 & & & \\
\hline $\mathrm{OPC}$ & 1.43 & 4.39 & 38 & & & \\
\hline Claims/conclusions & & & & 3.01 & 61.14 & .004 \\
\hline $\mathrm{HPC}$ & .58 & .93 & 6 & & & \\
\hline $\mathrm{OPC}$ & .10 & .40 & 3 & & & \\
\hline
\end{tabular}

\section{Students' interaction}

In groups, students could view each other's highlights and sticky notes, and comment on them. Altogether, students in two classes made 66 comments on group members' notes; only two were produced by OPC students. Twenty-seven HPC students (63\%) received an average of 2.4 comments. The interactions via sticky notes were primarily in a format of "note-response". There were only two instances of two-level interaction where the authors of the original sticky notes replied to comments received. Further analysis of the contents of comments exchanged provided a better understanding of the nature and pattern of students' online interaction. A large proportion of sticky-note comments $(76 \%)$ concerned the expressions of opinions on highlighted passages of text or responses to original notes. For example, a student highlighted, "People against high-speed railway besieged legislation building" and added the note, "The venue where people gathered to protest high-speed rail". Another student commented on it by saying "I think it will cause inconvenience to others." Here, the student addressed both the highlight and sticky note by stating the opinion that besieging the legislature will cause inconvenience to others.

The other one-quarter of interactions involved peer assessment of annotation behaviours in which students identified mistakes or offered suggestion to fellow students' annotations. For instance, a student attached a note saying, "... should include air pollution control, water quality control, resources recycling, forest protection, etc." to the peer student's highlight of "green quality living sphere". The student confirmed peers' annotations by adding comments such as "very clear" or gave suggestions like "too simple, you should provide more details (in your annotation)".

Further analysis on the comments addressing the highlighted content or original notes revealed that about $60 \%$ of comments involved the expression of personal opinions on either the issue or preceding comments. Twelve percent of the comments involved providing further information to fellow students, and another $12 \%$ involved affirmative comments. Fifteen percent of comments involved questions or challenges. For example, a student highlighted, "40 billion expenditure can create 55 thousand jobs" and noted, "The jobs created are not enough". Another student challenged the comment by adding a rhetorical question: "55 thousand jobs are not enough?"

\section{Discussion}

This exploratory study examined how two classes of year 10 students used Diigo, an online annotation tool, to read and analyse online texts. We found that as in paper-based annotation, in online annotation highlighting was the most commonly used feature (Ovsiannikov, et al., 1999). Most students were able to extend their annotation behaviour to self-selected articles. The HPC and OPC showed little difference with respect to highlighting. 
Diigo's sticky-note feature supported different argumentation skills. It allowed students to add term definitions, analyse positions, give evidence and explanations and make claims or conclusions. An essential step in the process of reading-to-argue is that of identifying and understanding important concepts to construct arguments. To define key concepts, students must identify important issues and actively seek or link relevant information. This step helped students understand what they were reading, clarify issues and create links between old and new knowledge. It also facilitated conceptual understanding and change during argumentation. Second, labelling different positions might trigger deeper mental processes such as identifying and comparing. It could help students understand different theories and the conditions underlying different arguments. Third, adding explanations or evidence involved condensing, paraphrasing and interpreting original texts, an important step in the process of constructing claims (Kuhn, 1991; Toulmin, 1958). Finally, when students made claims or formed conclusions based on source texts, they moved beyond tagging and explaining to inferring. This marks the crucial step in the argumentation process of moving from evidence to conclusion. However, the number of claims or conclusions made via sticky notes was rather limited. This suggests that it is vital to scaffold students' online annotation in order to achieve higher levels of reasoning.

In reading-to-argue, students used sticky notes to identify, understand, compare, explain and infer. Notetaking involves deeper cognitive processes than mere highlighting (Anderson \& Armbruster, 1982). Hence, we agree with Higgins (1993) that in reading-to-argue, adding notes is more important than merely identifying important points, as it involves building claims based on evidence. Using sticky notes is especially powerful when coupled with highlighting, which serves to contextualise sticky notes. Learners can take notes of personal meanings while reading, and engage in conversation with fellow students then and there.

The sticky-notes feature is versatile, combining tagging, linking, commenting and discussing. However, it met with different responses from the two classes. The OPC constructed significantly fewer sticky notes than The HPC with respect to both teacher-selected and self-selected texts. The HPC also defined more terms and drew more conclusions than The OPC. This implies that the HPC students were more willing and able to add sticky notes to assist in understanding and making inferences.

The social functions of Diigo allowed students to share and access the work of others, and encouraged evaluation and discussion among groups of students. The students seemed more interested in sharing their opinions and thoughts than in evaluating each other's annotations. However, interactions via sticky notes were limited in terms of the quantity of comments and the depth of conversations. In particular, the OPC students barely communicated on Diigo. Evaluating annotation requires a higher level of cognitive skills than stating one's own opinions. It involves the process of understanding, comparing and judging the quality of arguments. The fact that the OPC students only occasionally posed questions and challenged the opinions of others points to a need to provide more scaffolding and guidance to foster active and collaborative learning.

\section{Conclusion}

Overall, our findings echo earlier studies on paper-based annotation (Simpson \& Nist, 1990) in that annotation seems to foster active learning among individual learners. We concur with Greenhow (2009) that Diigo has the potential to enable students to become more attentive, reflective and critical while engaged in the process of reading-to-argue. Certainly, this study has several limitations. The sample size is rather small. Since intact classes were used in the study without the involvement of a control group, it is hard to attribute students' performance to the use of Diigo. Besides, only one module is examined, which makes it hard to attribute its impact on the learning outcome. Future study should involve more students in longer practice. Although our findings are preliminary, online annotation tools like Diigo are promising devices for facilitating reading-to-argue.

The findings of this study can be of much value for teachers and researchers to better design and use the online annotation tool to foster argumentative reading and writing. In particular, it points to the need to pay heed to the different needs of students of various ability levels, and to offer resources and support for fostering higher levels of argumentative reading and student collaboration. This study's insights into how students employed Diigo for argumentative reading could inform future study in this area. Interactive argumentation literature (e.g. Nussbaum, 2008) can be used to structure annotations, which might help 
ordinary-performance students in particular to be more engaged with online interaction. To better determine the pedagogical merits of annotation tools, a quasi-experimental study can be conducted where a control group with similar academic performance and technical skills will be incorporated. Empirical evidence will tell if the tools will make a difference in learning performance.

\section{Acknowledgements}

The study described in this paper was substantially supported by a grant from the Research Grants Council of the Hong Kong Special Administrative Region, China (Project No. HKU747909/2009/Social Science and Humanities) to Dr. Jingyan Lu. We would like to thank the support from our colleagues at the Centre for Information Technology in Education (CITE) of the University of Hong Kong. We are especially grateful to Dr Nancy Law for her insightful comments and support at every stage of the study. We also want to thank the teachers involved in this study: Miss Kwok Siu Mei, Mr Lai Ho Yam, and Mr Lo Ching Man. Their enthusiasm for applying technology in LS motivates us to run this study.

\section{References}

Anderson, T. H., \& Armbruster, B. B. (1982). Reader and text-studying strategies. In W. Otto \& S. White (Eds.), Reading expository material (pp. 219-242). New York: Academic Press.

Asterhan, C. S. C., \& Schwarz, B. B. (2009). Argumentation and explanation in conceptual change: Indications from protocol analyses of peer-to-peer dialog. Cognitive Science, 33(3), 374-400.

Brem, S. K., \& Rips, L. J. (2000). Explanation and evidence in informal argument. Cognitive Science, 24(4), 573-604.

Chang, S.-N., \& Chiu, M.-H. (2008). Lakatos' scientific research programmes as a framework for analysing informal argumentation about socio-scientific issues. International Journal of Science Education, 30(13), 1753-1773.

Clark, D., Sampson, V., Weinberger, A., \& Erkens, G. (2007). Analytic frameworks for assessing dialogic argumentation in online learning environments. Educational Psychology Review, 19(3), $343-$ 374.

Driver, R., Newton, P., \& Osborne, J. (2000). Establishing the norms of scientific argumentation in classrooms. Science Education, 84, 287-312.

Education and Manpower Bureau. (2007). Background. Liberal Studies: Currlculum and Assessment Guide (Secondary 4-6). Hong Kong.

Erduran, S., Simon, S., \& Osborne, J. (2004). TAPping into argumentation: Developments in the application of Toulmin's Argument Pattern for studying science discourse. Science Education, 88(6), 915-933.

Felton, M., \& Kuhn, D. (2001). The development of argumentative discourse skill. Discourse Processes, $32(2 \& 3), 135-153$.

Felton, M. K. (2004). The development of discourse strategies in adolescent argumentation. Cognitive Development, 19(1), 35-52.

Glassner, A., Weinstoc, M., \& Neuman, Y. (2005). Pupils' evaluation and generation of evidence and explanation in argumentation. British Journal of Educational Psychology, 75, 105-118.

Glover, I., Xu, Z., \& Hardaker, G. (2007). Online annotation - Research and practices. Computers \& Education, 49(4), 1308-1320.

Greenhow, C. (2009). Social scholarship: Applying social networking technologies to research practices. Knowledge Quest, 37(4), 42-47. 
Higgins, L. (1993). Reading to argue: Helping students transform source texts. In A. Penrose \& B. Sitko (Eds.), Hearing ourselves think: Cognitive research in the college writing classroom (pp. 70-101). New York: Oxford University Press.

Hwang, W. Y., Shadiev, R., \& Huang, S. M. (2011). A study of a multimedia web annotation system and its effect on the EFL writing and speaking performance of junior high school students. ReCALL, 23(2), 160-180.

Johnson, T. E., Archibald, T. N., \& Tenenbaum, G. (2010). Individual and team annotation effects on students' reading comprehension, critical thinking, and meta-cognitive skills. Computers in human behavior, 26(6), 1496-1507.

Knudson, R. E. (1992). The development of written argumentation: An analysis and comparison of argumentative writing at four grade levels. Child Study Journal, 22(3), 167-184.

Kuhn, D. (1991). The skills of argument. Cambridge: Cambridge University Press.

Kuhn, D. (2001). How do people know? Psychological Science, 12(1), 1-8.

Marshall, C. C. (1997). Annotation: from paper books to the digital library. Paper presented at the second ACM international conference on Digital libraries, Philadelphia, PA.

Nokelainen, P., Miettinen, M., Kurhila, J., Floréen, P., \& Tirri, H. (2005). A shared document-based annotation tool to support learner-centred collaborative learning. British Journal of Educational Technology, 36(5), 757-770.

Nussbaum, E. M. (2002). Scaffolding argumentation in the social studies classroom. The Social Studies, 93(2), 79-83.

Nussbaum, E. M. (2008). Collaborative discourse, argumentation, and learning: Preface and literature review. Contemporary Educational Psychology, 33(3), 345-359.

O'Hara, K., \& Sellen, A. (1997). A comparison of reading paper and on-line documents. Paper presented at the SIGCHI conference on Human factors in computing systems, Atlanta, Georgia.

Oaksford, M., Chater, N., \& Hahn, U. (2008). Human reasoning and argumentation: The probabilistic approach. In J. Adler \& L. Rips (Eds.), Reasoning: Studies of human inference and its foundations (pp. 383-413). New York: Cambridge University Press.

Osborne, J., Erduran, S., \& Simon, S. (2004). Enhancing the quality of argumentation in school science. Journal of Research in Science Teaching, 41(10), 994-1020.

Ovsiannikov, I. A., Arbib, M. A., \& McNeill, T. H. (1999). Annotation technology. International Journal of Human-Computer Studies, 50(4), 329-362.

Rau, P. L., Chen, S. H., \& Chin, Y. T. (2004). Developing web annotation tools for learners and instructors. Interacting with Computers, 16(2), 163-181.

Reznitskaya, A., Anderson, R. C., McNurlen, B., Nguyen-Jahiel, K., Archodidou, A., \& Kim, S.-Y. (2001). Influence of oral discussion on written argument. Discourse Processes, 32(2/3), 155-175.

Simpson, M. L., \& Nist, S. L. (1990). Textbook annotation: An effective and efficient study strategy for college students. Journal of Reading, 34(2), 122-129.

Stein, N. L., \& Bernas, R. (1999). The early emergence of argumentative knowledge and skill. In J. Andriessen \& P. Corrier (Eds.), Foundations of argumentative text processing (pp. 97-116).

Amsterdam: Amsterdam University Press. 
Australasian Journal of Educational Technology, 2013, 29(2).

Toulmin, S. E. (1958). The use of argument. Cambridge: Cambridge University Press.

Walton, D. N. (1996). Argumentation schemes for presumptive reasoning. Mahwah, NJ: Lawrence Erlbaum Associates.

Wolfe, J. (2008). Annotations and the collaborative digital library: Effects of an aligned annotation interface on student argumentation and reading strategies. International Journal of ComputerSupported Collaborative Learning, 3(2), 141-164. doi:10.1007/s11412-008-9040-x

Wolfe, J. L. (2002). Annotation technologies: A software and research review. Computers and Composition, 19(4), 471-497.

Wolfe, J. L., \& Neuwirth, C. M. (2001). From the margins to the center: The future of annotation. Journal of Business and Technical Communication, 15(3), 333-371.

Corresponding author: Jingyan Lu, jingyan@hku.hk

Australasian Journal of Educational Technology (C) 2013.

Please cite as: Lu, J., \& Deng, L. (2013). Examining students' use of online annotation tools in support of argumentative reading. Australasian Journal of Educational Technology, 29(2), 161-171. 